\title{
Correction to: Thermal annealing-induced modification of the structure and electrical conductivity of metallic nanotubes embedded in PET track-etched membranes
}

\author{
Artem L. Kozlovskiy ${ }^{1,2} \cdot$ Dmitriy I. Shlimas ${ }^{1,2} \cdot$ Maxim V. Zdorovets ${ }^{1,2,3} \cdot$ Anastassiya A. Mashentseva $^{1,2}$. \\ Kairat K. Kadyrzhanov ${ }^{1,2}$
}

Published online: 27 February 2018

(c) Institute of Chemistry, Slovak Academy of Sciences 2018

\section{Correction to: Chem. Pap. (2018) 72:173-180 https://doi.org/10.1007/s11696-017-0268-7}

In the original version of this article, the first affiliation was incorrect. Please see below the correct affiliation:
Institute of Nuclear Physics Republic of Kazakhstan, Ibragimov str., 1, Almaty 050032, Kazakhstan

The original article can be found online at https://doi.org/10.1007/ s11696-017-0268-7.

Anastassiya A. Mashentseva mashentseva.a@gmail.com

1 Institute of Nuclear Physics Republic of Kazakhstan, Ibragimov str., 1, Almaty 050032, Kazakhstan

2 The L. N. Gumilyov, Eurasian National University, Satpaev str., 5, Astana 010008, Kazakhstan

3 Ural Federal University, Mira str. 19, Yekaterinburg 620002, Russia 